\title{
Oscar's Shadow. Wilde, Homosexuality and Modern Ireland
}

\section{Bertrand Cardin}

\section{(2) OpenEdition}

\section{Journals}

Édition électronique

URL : https://journals.openedition.org/etudesirlandaises/3229

DOI : 10.4000/etudesirlandaises.3229

ISSN : 2259-8863

\section{Éditeur}

Presses universitaires de Caen

\section{Édition imprimée}

Date de publication : 30 octobre 2012

Pagination : 168-169

ISBN : 978-7535-2158-2

ISSN : 0183-973X

\section{Référence électronique}

Bertrand Cardin, «Oscar's Shadow. Wilde, Homosexuality and Modern Ireland », Études irlandaises [En ligne], 37-2 | 2012, mis en ligne le 30 octobre 2012, consulté le 27 juillet 2022. URL : http:// journals.openedition.org/etudesirlandaises/3229; DOI : https://doi.org/10.4000/etudesirlandaises. 3229

Ce document a été généré automatiquement le 27 juillet 2022.

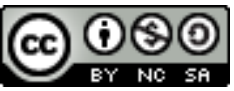

Creative Commons - Attribution - Pas d'Utilisation Commerciale - Partage dans les Mêmes Conditions 4.0 International - CC BY-NC-SA 4.0

https://creativecommons.org/licenses/by-nc-sa/4.0/ 


\title{
Oscar's Shadow. Wilde, Homosexuality and Modern Ireland
}

\author{
Bertrand Cardin
}

1 Après avoir dirigé un certain nombre d'ouvrages collectifs (Sex, Nation and Dissent) et des recueils d'essais sur les œuvres de Kate O'Brien, Molly Keane ou Elizabeth Bowen, Eibhear Walshe, enseignant-chercheur à University College Cork, signe ici un ouvrage consacré à Oscar Wilde et plus largement à la thématique de l'homosexualité en Irlande. Oscar's Shadow se donne pour objectif de circonscrire la manière dont l'homosexualité est perçue dans la culture irlandaise depuis 1895, année de la disgrâce de l'auteur de Dorian Gray. L'essai s'intéresse à la représentation et à l'influence de Wilde dans la sphère culturelle irlandaise des $\mathrm{xx}^{e}$ et $\mathrm{xxI}^{\mathrm{e}}$ siècles, ne s'attachant pas tant à l'homme réel qu'à ce qu'on a fait de lui au fil du temps. Partant du présupposé que la personne d'Oscar Wilde cristallise le discours sur l'homosexualité en Irlande, Eibhear Walshe étudie parallèlement l'évolution de la perception irlandaise de Wilde et de l'homosexualité. Pour ce faire, il exploite des documents d'archives, des extraits de journaux relatant les trois procès engagés contre Wilde, et recense des textes divers sur la vie de l'écrivain (études critiques, biographies, romans, pièces de théâtre...) Les sept chapitres de l'étude couvrent un spectre chronologique allant de 1884 à 2010, chacun d'eux traitant d'une période de dix à quarante années.

Lors des procès, le discours public britannique témoigne d'une virulence homophobe à l'égard d'un homme clairement identifié comme « autre » de par ses racines celtes mais aussi son orientation sexuelle, et qui, de surcroît, ose publiquement affirmer sa différence. Aussi, dans les années suivant les procès, l'Angleterre s'empresse de reléguer aux oubliettes ce nom couvert d'opprobre.

3 En Irlande, en revanche, de nombreuses réactions, bien qu'embarrassées, se montrent relativement discrètes et dévient le propos en ne se focalisant pas tant sur la sexualité de l'auteur que sur sa nationalité. Des hommes de lettres, tels Shaw, Yeats ou Joyce, considèrent Wilde comme une figure emblématique de la dissidence nationaliste, eu égard notamment à l'engagement républicain de sa mère. Le nom de Wilde est exploité comme celui d'un héros tragique, voire d'un martyr. La presse nationale exprime 
également une certaine forme de compassion à l'égard de ce "génie malheureux 》 (The Irish Times, 1906). Selon Walshe, à l'aube du XX $\mathrm{XX}^{\mathrm{e}}$ siècle et par la suite, y compris durant les années de l'Etat libre, l'Irlande ne renie pas Wilde, bien au contraire : elle ne cesse de promouvoir ses écrits et de mettre en scène ses pièces dans les théâtres de Dublin et de Belfast.

4 Selon une approche chronologique, discutable car donnant parfois une impression de catalogue, Walshe montre que chaque personnalité de la sphère culturelle irlandaise de l'époque se positionne par rapport à Wilde : il recense les artistes qui le mentionnent dans leurs mémoires ou leur correspondance et ceux qui, alors qu'ils l'ont côtoyé, prétendent ne pas l'avoir connu. Certains intellectuels prennent sa défense, d'autres se montrent farouchement hostiles, émettant même parfois le regret qu'Oscar ne fût pas mort en bas âge comme sa sœur...

A partir des années 1960, des écrivains et critiques se réapproprient le nom de Wilde, lequel devient symbole de modernité et de tolérance, même si de nombreux stéréotypes demeurent profondément ancrés dans les mentalités.

6 L'auteur et son œuvre font l'objet d'importantes manifestations à la fin du $\mathrm{xx}^{\mathrm{e}}$ siècle, notamment après 1993, date-clé de la décriminalisation de l'homosexualité en Irlande : summer schools, conférences, expositions, érections de monuments...

7 Durant cette période et depuis lors, de nombreux textes reconsidèrent, réinventent Oscar Wilde, mais aussi sa mère, Speranza, son épouse, Constance, ou son amant, Bosie, comme en témoignent les pièces d'Eagleton ou de Kilroy, ou encore les approches contrastées des études de McCormack ou de Kiberd.

Aujourd'hui, de l'avis de Walshe, Wilde est devenu une véritable icône gay : il a ouvert la voie à toute une génération d'auteurs qui ne cachent pas leur homosexualité, tels Colm Toibin, Keith Ridgway, Mary Dorcey ou Emma Donoghue...

9 Malgré la sélection nécessairement subjective opérée par Walshe, suscitant de la part du lecteur un questionnement sur la possible partialité de l'auteur en faveur de Wilde, et en dépit de la monotonie que peut engendrer l'approche chronologique sur une si longue période, cette publication est fort intéressante et mérite d'être lue, essentiellement parce qu'elle retrace un vaste panorama de la culture irlandaise du $\mathrm{xx}^{\mathrm{e}}$ siècle sous l'angle original de la réception.

\section{AUTEURS}

\section{BERTRAND CARDIN}

Université de Caen-Basse Normandie 